\title{
Online Social Networking in the Teaching of English as a Foreign Language
}

\author{
Manssour Mohammad Ras'n Habbash ${ }^{1}$ \\ ${ }^{1}$ Community College, University of Tabuk, Saudi Arabia \\ Correspondence: Manssour Mohammad Ras'n Habbash, Community College, University of Tabuk, Saudi Arabia. \\ E-mail: research2015ut@gmail.com
}

Received: November 21, 2018

Accepted: December 11, 2018 Online Published: February 24, 2019

doi:10.5539/ijel.v9n2p189

URL: https://doi.org/10.5539/ijel.v9n2p189

\begin{abstract}
The online social networking sites like the Facebook, Google+, Twitter, LinkedIn and WhatsApp are the most widely used platforms for routinely essential communications. However, the role and implications of using online social networking sites in teaching still remain unestablished (Roblyer et al., 2010). In view of the ever-advancing trends in using online social networking, a study of the EFL teachers' extent of using digital social networking is taken up at the University of Tabuk in Saudi Arabia. A group of English language teachers at the university were consulted for the data required for analysis. The study employed a mixed methods research approach that entailed a survey questionnaire on Likert scale distributed to a sample of teachers. The data obtained from the survey questionnaire were subjected to Cronbach's alpha test for measuring the internal consistency of the items. After confirming the internal consistency of the items, the same questionnaire was employed for semi-structured face-to-face interviews that included a discussion on the opinions of other respondents and their responses were again registered for comparison. The resultant final data were analyzed qualitatively in light of Jenness's (1932) conformity theory to establish whether the teachers are comfortably in favor of using online social networking for teaching purposes. And the inferences drawn from the analysis are provided for further insight into the use of social networking in the teaching of English.
\end{abstract}

Keywords: online social networking, Facebook, WhatsApp, EFL teaching, faculty conformity

\section{Introduction}

Students everywhere and the faculty are much aware of the importance of online social networking for their everyday communication. However, there are some conflicting views about the integration of online social networking sites in teaching, which is more prominent in the teaching of English as a Foreign Language. Although many teachers at university level are using online social networking sites for their teaching purposes and many studies find that online social networking is a productive teaching platform, the role of the platform in teaching is unestablished. This study aims at laying a step further towards establishing the role of the social networking media in teaching EFL.

The use of social networking as a means of communication in all walks-of-life all over the world is continuously on ascent while its role in teaching and the extent of its use for teaching purposes remains still unestablished. With an assumption that online social networking is being used by many teachers of EFL for their teaching purposes, the study aims at filling the void of establishing the role of social networking in teaching as well as to bring forth the extent of the use of social networking that entails their conformity and comfort levels in the teaching of English by the EFL teachers at the University of Tabuk. However, as the study is confined to a group of EFL teachers at the University of Tabuk in Saudi Arabia, the generalizations of the output can be seen more appropriate to the teachers in the Middle East and to a greater extent to the EFL teachers in Saudi Arabia. Moreover, in view of the limitations in the sampling, the output of the study may not be comprehensive and so further follow up studies are recommended.

The study employs both qualitative and quantitative methods of research for analysis of the data gathered. The data required would be obtained from a group of EFL teachers working at the university of Tabuk that will be selected by purposive sampling method. The sample of teachers will be provided with a questionnaire set on a Likert scale that will be followed by face-to-face semi-structured interviews for obtaining the data required for analysis. The qualitative data of the responses will be subjected to Cronbach's alpha test for measuring the 
internal consistency of the Likert items and the data will be analyzed quantitatively to find the extent of the use of online social working in EFL teaching. The qualitative data that are obtained through face-to-face interviews will be analyzed for establishing the role of social networking in EFL teaching. The inferences drawn from the results of the study will be used in making recommendations about the use of online social networking for pedagogical purposes that can further be used in teacher training programs.

\section{Literature Review}

Online sources clarify that social networking is the biggest platform for making and expanding connections and businesses amongst the people from any part of the planet through the social media sites such as Google+, Linkedin, Facebook, Twitter, and WhatsApp etc. (Rouse, n.d.). The social networking that is based on the "six degrees of separation concept" (Lawrence \& Latha, 2015) enables the people from any part of the world establish connections with the people in any other part via interconnected online communities that are in turn based on the theory that a person in one part of the world can be connected with a person in any other of the world by no more than three intermediaries. See the following link for a brief history of the social media (https://youtu.be/bi3DoRWngOs). Prensky (2001) describes the present generation of students as digital natives. That means the students nowadays are completely surrounded by digital media viz. televisions, computers, videogames, cellphones, digital cameras and all the other digital tools that they always use. The digital natives' thinking process is said to be developing much differently from the thinking processes of the non-digital people who are a generation older. At the same time, many of the teachers for the digital natives belong to older non-digital generation that is described as digital immigrants and so there is an immense requirement for these digital immigrant teachers to upgrade themselves to the level of the thinking process of their students.

The study of Andrei (2017) mentions that the most commonly used and the most available technology in classrooms would be the "digital boards, overhead projectors for the digital boards, document cameras, laptops, desktops, iPods, iPads, and internet connection for all devices." The study observes that the availability of technology doesn't mean that technology is automatically integrated into the classroom instructional activities. There are several issues to be considered for enhancing technology integration in classrooms. The issues like the availability of enough class time, technology malfunctioning while working in the classroom, and the teacher efficacy in integrating technology in their classroom activities as well as students' awareness of using the integrated technology for learning purposes in classrooms. Moreover, the similar studies state that the efficacy of the teachers who have attended training programs on the integration of digital media in classrooms are more effective in integrating technology in their classrooms.

Blattner and Fiori (2009) identify that Facebook group members can develop their communicative, pragmatic and linguistic competence by having exposure to several "linguistic varieties and colloquialisms that language departments and text books cannot match." Observation of natural speech acts and information gathering becomes much easier with the social networking sites that can provide the group members with first-hand information and live observation of the facts about a language and culture that is essential for developing the pragmatics of a language. It is observed that as most of the student communities hold a positive impression about the teachers who integrate technology with their classroom teaching, the faculties as well are thinking about the ways of integrating high tech and e-learning methods into their curricula in order to get themselves sync with the expectations of their students.

In spite of the distinctiveness between Internet and the web, for common users of the digital gadgets they are the communication tools that are interconnected and integrated as the users can switch over from one application to another with in no time. In the view of Bosch (2009), ICT (Information and Communication Technology) is a major communication platform for personal as well as social communication. Bosch (ibid) mentions that in spite of the unproductive investment of time and energies on the social networking sites like Facebook, the students at the university of Cape Town use Facebook extensively for sharing classroom content, for informally exchanging the courser related discussions and questions, and for making friends fast through such exchanges. The major logistical issue that many ICT users confront is the bandwidth restrictions. With limited bandwidth availability at many of the universities in the world, the unsuccessful attempts of audio and video streaming usually make it difficult to use face book for teaching and learning purposes. However, many teachers and even universities are taking initiation to integrate teaching and learning with the tools like Facebook by developing their own Facebook applications for pedagogical purposes. Wu, Yen, and Marek (2011) find that the interactive English language instruction with the help of online sources, particularly video conferencing, improves the English language ability of the learners by building their confidence and motivation levels. Based on the constructivist educational theory that advocates an active engagement of learners in a learning process makes learning joyful and develops autonomous learning for enjoyment, the scholars found that the creation of live interactive 
environment using online sources like video conferencing makes the learning more meaningful as they come to know about the purpose of learning livelier. It's argued that learning is more fun and enjoyable to learners when the learning process improves their motivation and confidence, which is much easier by the use of online sources.

The Internet social networking applications such as face-book, the social networking cum micro-blogging applications such as Twitter and the personal communication applications that resemble micro blogs that function like WhatsApp can all be integrated and used for sharing, developing and for holding discussions on the topics of interest relevant to the teaching learning content (Galien \& Bowcher, 2010). When some information related to a topic in the form of a video, a reading text or a listening text is shared amongst the students in a class they can start commenting on the topic, express their opinions, look at and listen to the opinions of the other students and collaborate to improve their language, communication, critical thinking, political and the relevant social skills that they need in their life for carrying successful projects. Dooly and Masats (2010) believe that teachers can enable the learners to develop their audiovisual and linguistic competences, ICT competences and inter and intra personal competences. At the same time, it is essential that all the teachers need to be provided with the teacher training programs required for possessing such competences along with the tools required for integrating language and technology in their teaching practice. It is argued in many scholarly works that teachers need to make a great shift from the conventional teachers centered interactions to the interactions that require the adoption of new tools that involve interaction amongst teachers, technology and learners.

Commenting on the importance of process writing approach for improving the writing skills of students, Boas (2011) mentions about the potential of Internet in offering multiple resources that can be used in every step of the process writing method. Developing writing skills entails socioconstructivist thought process that advocates the necessity to observe closely into the aspects of the topic, its relevance to the society around the target readers, the purpose for writing, the writers' connection to the society and the language that needs to be use for such writing etc. In view of the requirements of what the process writing demands, it is suggested that Internet sources such as blogs, wikis, and the social networking sites provide language learners with the essential elements of the writing process. When the effectiveness of the online writing activities by using blogs, wikis and forums is examined, Miyazoe and Anderson (2010) identified that blended writing course designs are much favored by the students with wiki being the most favored online activity. It is also understood that students develop their ability to differentiate the styles of writing projected by various writers in blogs and forums. The variations in writing styles that can be observed in the texts of these online sources, when blended in the writing courses provide the learners with the required challenges and fun for working on the activities.

As it is mentioned in many other scholarly works, Chartrand (2012) also clarifies that the Internet proves to be a vast and unique source of authentic written, audio and video materials for English language learners as well as for English language teachers to supplement their teaching materials. Especially the social networking sites have created an opportunity for language learners to interact with their peers in an authentic way in order to improve their speaking and writing skills. However, the teachers need to spend time on learning the ways of using the web 2.0 tools and must be aware well of the privacy and security requirements to be followed while dealing with the content that is posted by them and while using the content that is posted by their students. Tess (2013) finds that the use of social networking sites for instruction in classroom is mostly confined to the choices of instructors and so it remained at the level of instructors and not a mandatory implementation from the institutes' side. In spite of the ever-growing arguments in favor of the purposeful integration of social working site in higher education, there is a great dearth for empirical evidences in support of such arguments. However, it is considered an unquestionable fact that the use of social networking sites is more prevalent at university campuses than anywhere else and most of the instructors are envisioning the scope for a complete integration of the social networking sites into their teaching. Yang (2009) brings forth the possibilities of using blogs as tools for creating communities of practices that enable the learners and teachers to reflect on what they learn and practice reflectively both in learning and teaching. Communities of practices can be either teachers' or students' as well as of the communities that can include both teachers and students. When a community of practice is created online, the members can contribute the outcomes of their thought processes by messaging on the blogs and the members can think reflectively on all the contributions, which in turn keeps them developing critically as well as professionally. On the other hand, the societies where the learner behaviors are supposed to be based on the Confucius' teachings that advocate the learners to be obedient, moderate and unquestioning, the communities of practice can bring about a great change in transforming them to be thinkers that are more reflective.

In spite of the plethora of advantages that online networking sites bring for teachers there are some downsides that teachers need to be careful about. Carter, Foulger, and Ewbank, (2008) write about the consequences of 
being unprofessional in their role as teachers of an institution in using social networking sites in classrooms as well as outside the classrooms. As it is easier to create personal identities both for teachers and students, there is every possibility that teachers tend to give their students an access to the information about their personal lives or students take advantage of looking into the private affairs of their teachers or teachers tend to gain access to the private information of their students and so on. Teachers need to be completely aware of the consequences of such unprofessional tendencies that may cause them lose their teacher authority, which in turn may jeopardize their jobs and careers. At the same time, there is a great necessity to being innovative for teachers. And those that are innovative even in the manner of their conduct and take risk of their innovative approaches can create new opportunities and ways of dealing with students. However, teachers need to go carefully with a balance of their experimentation and their professionalism for the sake of the safety of their jobs and careers.

\section{Methodology and Data Analysis}

In most of the research works, developing a scale in a survey questionnaire for measuring the underlying constructs of the research work is an essential basic step that needs to be accomplished for collecting the data relevant for analysis. And the summative data obtained by executing the survey instrument is supposed to result in the predictor variables for analysis. However, when the scales are set to encompass the realm of prediction the summative data need to be subjected to a reliability test such as Cronbach's alpha for strengthening the reliability of the results of the research work (Santos, 1999). Chronbach's alpha is the correlation between the score of a scale item and the total score of each observation of a respondent that is compared to the variance of the total scores of all the items of the scale. The alpha is usually defined as

$$
\alpha=\frac{N \cdot \bar{c}}{\bar{v}+(N-1) \cdot \bar{c}}
$$

where

$$
\begin{aligned}
& \mathrm{N} \text { refers to the number of scale items } \\
& \overline{\mathrm{c}} \text { refers to the average of all covariances between items } \\
& \overline{\mathrm{v}} \text { refers to the average variance of each item }
\end{aligned}
$$

The questionnaire of this study comprises 13 Likert items that refers to dependent variables and two open-ended questions that refer to independent variables and are related to the social networking sites that the respondents prominently use for different purposes. While the 13 Likert items were used for qualitative and quantitative analysis, the other two questions were used exclusively for obtaining the data for qualitative analysis. Once the data from the respondents were registered, they were subjected to quantitative analysis for obtaining Chronbach's alpha as well as the other statistical data required. The usual range of Cronbach's alpha reliability coefficient is 0 and 1 . As there is no mention about the lower limit to the coefficient it can be noticed that the closer the coefficient to 1.0 the higher is the internal consistency of the scale. The Table 1 below gives a good view of the Cronbach's alpha and the internal consistency relation.

Table 1. Chronbach's consistency ranking

\begin{tabular}{ll}
\hline Cronbach's alpha & Internal consistency \\
\hline$\alpha \geq 0.9$ & Excellent \\
$0.9>\alpha \geq 0.8$ & Good \\
$0.8>\alpha \geq 0.7$ & Acceptable \\
$0.7>\alpha \geq 0.6$ & Questionable \\
$0.6>\alpha \geq 0.5$ & Poor \\
$0.5>\alpha$ & Unacceptable \\
\hline
\end{tabular}

Source: George \& Mallery, 2003, p. 231.

The Table 2 below provides details of the reliability test that is under taken to obtain Cronbach's alpha. The results in the table are obtained by using Del Siegle's reliability calculator. The advantage with Siegle' s reliability calculator is that it gives the reliability test values that can be measured in other ways as well, viz. Split-half (odd-even) correlation, KR21 etc. Table 2 gives us the values of the present survey model that is tested for its reliability and internal consistency. The result shows that Cronbach's Alpha of the survey tool of this study is 0.97 , which means that the internal consistency and the reliability of the tool can be considered excellent. 
Table 2. Results of the reliability test

\begin{tabular}{ll}
\hline Cronbach's Alpha & 0.978142247 \\
Split-Half (odd-even) Correlation & 0.978429979 \\
Split-Half with Spearman-Brown Adjustment & 0.989097405 \\
Mean for Test & 48.77777778 \\
KR21 (use only 0 and 1 to enter data for this) & 2.549763476 \\
KR20 (use only 0 and 1 to enter data for this) & 2.559649778 \\
\hline
\end{tabular}

Having confirmed the internal consistency and the reliability of the Likert items, the data of the registered responses were analyzed for the ' $\mathrm{P}$ ' value. The data relevant to 18 teachers was analyzed for their responses to the 13 Likert items. So, the ' $\mathrm{N}$ ' value refers to the number of Likert items that have 'excellent' internal consistency. For the sake of subjecting the data to ' $\mathrm{t}$ ' test and for obtaining the 'p' value the data relevant to the teachers in favor of using online social networking was considered for treatment 1 of the ' $t$ ' test and the data relevant to the teachers not in favor of social networking sites was considered for treatment 2 of the ' $t$ ' test. The responses considered for treatment 1 are the cumulative of the agreed and strongly agreed and the responses considered for treatment 2 become the cumulative of the disagreed and strongly disagreed.

Table 3. Quantitative data for analysis

\begin{tabular}{llllll}
\hline Item & Strongly Disagree & Disagree & Neutral & Agree & Strongly Agrees \\
\hline 1 & $0(0.0 \%)$ & $3(16.6 \%)$ & $0(0.0 \%)$ & $11(61 \%)$ & $4(22.2 \%)$ \\
2 & $0(0.0 \%)$ & $4(22.2 \%)$ & $0(0.0 \%)$ & $12(66.6 \%)$ & $2(11.1 \%)$ \\
3 & $1(5.5 \%)$ & $3(16.6 \%)$ & $0(0.0 \%)$ & $12(66.6 \%)$ & $2(11.1 \%)$ \\
4 & $0(0.0 \%)$ & $1(5.5 \%)$ & $0(0.0 \%)$ & $11(61 \%)$ & $6(33.3 \%)$ \\
5 & $0(0.0 \%)$ & $5(27.7 \%)$ & $1(5.5 \%)$ & $10(55.5 \%)$ & $2(11.1 \%)$ \\
6 & $0(0.0 \%)$ & $1(5.5 \%)$ & $3(16.6 \%)$ & $11(61 \%)$ & $3(16.6 \%)$ \\
7 & $0(0.0 \%)$ & $2(11.1 \%)$ & $8(44.4 \%)$ & $6(33.3 \%)$ & $2(11.1 \%)$ \\
8 & $0(0.0 \%)$ & $0(0.0 \%)$ & $0(0.0 \%)$ & $13(72.2 \%)$ & $5(27.7 \%)$ \\
9 & $0(0.0 \%)$ & $1(5.5 \%)$ & $5(27.7 \%)$ & $10(55.5 \%)$ & $2(11.1 \%)$ \\
10 & $0(0.0 \%)$ & $2(11.1 \%)$ & $4(22.2 \%)$ & $8(44.4 \%)$ & $4(22.2 \%)$ \\
11 & $0(0.0 \%)$ & $2(11 \%)$ & $2(11.1 \%)$ & $12(66.6)$ & $2(11.1 \%)$ \\
12 & $0(0.0 \%)$ & $1(5.5 \%)$ & $5(27.7 \%)$ & $11(61 \%)$ & $1(5.5 \%)$ \\
13 & $1(5.5 \%)$ & $4(22.2 \%)$ & $4(22.2 \%)$ & $6(33.3 \%)$ & $3(16.6 \%)$ \\
\hline
\end{tabular}

Note. $\mathrm{N}=13$.

Percentage in favor (Agree+ Strongly Agree): $56.7+16.6=73.3$

Percentage not in favor (Strongly disagree +Disagree): $0.86+12.3=13.1$

Percentage of Teachers in neutral: 13.6

Table 3a. Data analysis of table 3

\begin{tabular}{llllllll}
\hline & Percentage & Mean & Median & Mode & Standard Deviation & Variance & Standard Error of the Mean \\
\hline Teachers in favor & 73.3 & 13 & 14 & 14,12 & 2.61 & 6.83 & 0.7250 \\
Teachers Against & 13.1 & 2.38 & 2 & 1 & 1.66 & 2.75 & 0.4604 \\
Teachers Neutral & 13.6 & 2.46 & 2 & 0 & 2.60 & 6.76 & 0.7216 \\
\hline
\end{tabular}

\section{Treatment 1}

$\mathrm{N}_{1}: 13$

$\mathrm{df}_{1}=\mathrm{N}-1=13-1=12$

$\mathrm{M}_{1}: 13.15$

$\mathrm{SS}_{1}: 93.69$

$\mathrm{s}^{2}{ }_{1}=\mathrm{SS}_{1} /(\mathrm{N}-1)=93.69 /(13-1)=7.81$

\section{Treatment 2}

$\mathrm{N}_{2}: 13$ 
$\mathrm{df}_{2}=\mathrm{N}-1=13-1=12$

$\mathrm{M}_{2}: 2.38$

$\mathrm{SS}_{2}: 33.08$

$\mathrm{s}_{2}^{2}=\mathrm{SS}_{2} /(\mathrm{N}-1)=33.08 /(13-1)=2.76$

\section{T-value Calculation}

$\mathrm{s}_{\mathrm{p}}^{2}=\left(\left(\mathrm{df}_{1} /\left(\mathrm{df}_{1}+\mathrm{df}_{2}\right)\right) * \mathrm{~s}_{1}{ }_{1}\right)+\left(\left(\mathrm{df}_{2} /\left(\mathrm{df}_{2}+\mathrm{df}_{2}\right)\right) * \mathrm{~s}_{2}{ }_{2}\right)=((12 / 24) * 7.81)+((12 / 24) * 2.76)=5.28$

$\mathrm{s}^{2}{ }_{\mathrm{M} 1}=\mathrm{s}_{\mathrm{p}}^{2} / \mathrm{N}_{1}=5.28 / 13=0.41$

$\mathrm{s}^{2}{ }_{\mathrm{M} 2}=\mathrm{s}_{\mathrm{p}}^{2} / \mathrm{N}_{2}=5.28 / 13=0.41$

$\mathrm{t}=\left(\mathrm{M}_{1}-\mathrm{M}_{2}\right) / \sqrt{ }\left(\mathrm{s}_{\mathrm{M} 1}^{2}+\mathrm{s}^{2}{ }_{\mathrm{M} 2}\right)=10.77 / \sqrt{ } 0.81=11.95$

The $t$-value is 11.94648 . The $p$-value is $<.00001$. The result is significant as $p<.05$.

The magnitude of the ' $\mathrm{t}$ ' value and the ' $\mathrm{p}$ ' value signify that teachers at the university are mostly in favor of using online social networking sites and so the role and implications of the sites in teaching are positive. However, in view of the possibility of obtaining a different data from the same sample of teachers when they are provided with the knowledge and awareness about the responses and opinions of other teachers, the same questionnaire was used for face-to-face interviews and for registering the responses on the spot.

Many of the conformity theories mention about the external factors like societal norms, money, the opinions of the people around etc. in influencing the judgments, behaviors and attitudes of individuals. Jenness (1932) has found that people tend to change their initial opinions and judgments about something when they are provided with an opportunity to discuss with other people around them. The study of Jenness finds that less intelligent people get benefited more by discussions on the opinions held by other people as they can go out of their confusion about their decisions before the discussion, and feel more secure by changing opinions in order to be on track with the mainstream people and their activities. To a similar extent the ascendant people who have leadership qualities also get benefited from discussions as they find it easier to steer a group towards a common goal when they are aware of the opinions of other people, since it's easier to lead a group and get them conformed to the judgment of a majority of the people. The test of conformity also indicates whether teachers are doing their work comfortably or by compulsion. A greater variation in their opinions before and after the discussions can clarify whether the teachers are working comfortably or not. In the present study case, it's whether the teachers are working with the social networking sites comfortably, with a greater understanding of their benefits, or whether they are into the sites by compulsion.

The semi structured face-to-face interviews were conducted with the same questionnaire after a few days of the initial questionnaire distribution and registration of responses. The interviews were conducted individually, with each participant in the sample, with a prior discussion on the relevant responses provided by the other participants. The discussion is between the interviewer and the participant only and not between or amongst the participants. However, the interview discussion was carried out intentionally by providing completely opposite opinions to what the other participants originally had provided in the first questionnaire. For each question in the interview, the interviewer recorded the participants' level of agreement again. The aim of this strategy is to check the impact of the opinions held by other participants in changing the earlier opinions of the participant being interviewed at that time. The present responses and the variation, if any, in the responses can reflect whether the teachers have a complete understanding and knowledge of the benefits of using the social networking sites and whether they are using them comfortably in their teaching, or whether they are using them by compulsion because the other teachers are using, and just to be in tune with the trend of technology. Table 4 below reflects the responses recorded after the interviews. 
Table 4. Quantitative data for analysis after face to face interviews

\begin{tabular}{llllll}
\hline Item & Strongly Disagree & Disagree & Neutral & Agree & Strongly Agrees \\
\hline 1 & $0(0.0 \%)$ & $3(16.6 \%)$ & $0(0.0 \%)$ & $8(44.4 \%)$ & $7(38.88 \%)$ \\
2 & $0(0.0 \%)$ & $4(22.2 \%)$ & $0(0.0 \%)$ & $12(66.6 \%)$ & $2(11.1 \%)$ \\
3 & $1(5.5 \%)$ & $3(16.6 \%)$ & $0(0.0 \%)$ & $12(66.6 \%)$ & $2(11.1 \%)$ \\
4 & $0(0.0 \%)$ & $1(5.5 \%)$ & $0(0.0 \%)$ & $11(61 \%)$ & $6(33.3 \%)$ \\
5 & $0(0.0 \%)$ & $2(11.1 \%)$ & $1(5.5 \%)$ & $10(55.5 \%)$ & $5(27.7 \%)$ \\
6 & $0(0.0 \%)$ & $1(5.5 \%)$ & $3(16.6 \%)$ & $11(61 \%)$ & $3(16.6 \%)$ \\
7 & $0(0.0 \%)$ & $2(11.1 \%)$ & $4(22.2 \%)$ & $8(44.4 \%)$ & $6(33.3 \%)$ \\
8 & $0(0.0 \%)$ & $0(0.0 \%)$ & $0(0.0 \%)$ & $13(72.2 \%)$ & $5(27.7 \%)$ \\
9 & $0(0.0 \%)$ & $1(5.5 \%)$ & $5(27.7 \%)$ & $10(55.5 \%)$ & $2(11.1 \%)$ \\
10 & $0(0.0 \%)$ & $2(11.1 \%)$ & $4(22.2 \%)$ & $8(44.4 \%)$ & $4(22.2 \%)$ \\
11 & $0(0.0 \%)$ & $2(11.1 \%)$ & $2(11 \%)$ & $12(66.6)$ & $2(11.1 \%)$ \\
12 & $0(0.0 \%)$ & $1(5.5 \%)$ & $5(27.7 \%)$ & $11(61 \%)$ & $1(5.5 \%)$ \\
13 & $2(11.1 \%)$ & $5(27.7 \%)$ & $4(22.2 \%)$ & $5(27.7 \%)$ & $2(11.1 \%)$ \\
\hline
\end{tabular}

Percentage in favor (Agree+ Strongly Agree): $55.9+20.05=75.9$

Percentage not in favor (Strongly disagree +Disagree): $1.27+11.5=12.7$

Percentage of Teachers in neutral: 11.9

Table 4a. Data analysis of table 4

\begin{tabular}{llllllll}
\hline & Percentage & Mean & Median & Mode & Standard Deviation & Variance & Standard Error of the Mean \\
\hline Teachers in favor & 75.9 & 13.53 & 14 & 14 & 2.53 & 6.43 & 0.7036 \\
Teachers Against & 12.7 & 2.15 & 2 & 1,2 & 1.46 & 2.14 & 0.4058 \\
Teachers Neutral & 11.9 & 2.15 & 2 & 0 & 2.07 & 4.30 & 0.5756 \\
\hline
\end{tabular}

\section{Treatment 1}

$\mathrm{N}_{1}: 13$

$\mathrm{df}_{1}=\mathrm{N}-1=13-1=12$

$\mathrm{M}_{1}: 13.54$

$\mathrm{SS}_{1}: 77.23$

$\mathrm{s}^{2}{ }_{1}=\mathrm{SS}_{1} /(\mathrm{N}-1)=77.23 /(13-1)=6.44$

\section{Treatment 2}

$\mathrm{N}_{2}: 13$

$\mathrm{df}_{2}=\mathrm{N}-1=13-1=12$

$\mathrm{M}_{2}: 2.15$

$\mathrm{SS}_{2}: 25.69$

$\mathrm{s}_{2}^{2}=\mathrm{SS}_{2} /(\mathrm{N}-1)=25.69 /(13-1)=2.14$

\section{T-value Calculation}

$\mathrm{s}_{\mathrm{p}}^{2}=\left(\left(\mathrm{df}_{1} /\left(\mathrm{df}_{1}+\mathrm{df}_{2}\right)\right) * \mathrm{~s}_{1}{ }_{1}\right)+\left(\left(\mathrm{df}_{2} /\left(\mathrm{df}_{2}+\mathrm{df}_{2}\right)\right) * \mathrm{~s}_{2}{ }_{2}\right)=((12 / 24) * 6.44)+((12 / 24) * 2.14)=4.29$

$\mathrm{s}^{2}{ }_{\mathrm{M} 1}=\mathrm{s}_{\mathrm{p}}^{2} / \mathrm{N}_{1}=4.29 / 13=0.33$

$\mathrm{s}^{2}{ }_{\mathrm{M} 2}=\mathrm{s}_{\mathrm{p}}^{2} / \mathrm{N}_{2}=4.29 / 13=0.33$

$\mathrm{t}=\left(\mathrm{M}_{1}-\mathrm{M}_{2}\right) / \sqrt{ }\left(\mathrm{s}_{\mathrm{M} 1}^{2}+\mathrm{s}_{\mathrm{M} 2}^{2}\right)=11.38 / \sqrt{ } 0.66=14.02$

The $t$-value is 14.01601 . The $p$-value is $<.00001$. The result is significant at $p<.05$.

The data analysis and the values above clarify that there is a very little influence of the discussions about the opinions held by others on the decision making of the participants in the context of the present study. The values signify that most of the teachers are not only in favor of using online social networking sites but also there are completely aware of the use of online sources and that they are using them in their classes very comfortably under no pressurized conditions. It is to be noted that the teachers agreed for the technological integration into 
their teaching of English irrespective of the prior discussions in which the participants were informed about the others opinions that were claimed to be quite against the use of social networking sites. We can notice that question number 7 has seen greater percentage of opinion shift from agreed towards neutrality. After the discussions, more teachers opted for being 'neutral' for their knowledge about the other teachers' integration of social networking sites into their teaching process. On the contrary, despite the interviewer's negative feedback about the use of social networking sites in teaching, more teachers have agreed strongly to the question number 1, which clarifies that the teachers are completely aware of the benefits of integrating social networking sites in teaching.

Table 5. Qualitative data for analysis

\begin{tabular}{ll}
\hline Social Networking Site & Percentage of Teachers Using \\
\hline Facebook & $32 \%$ \\
Twitter & $12 \%$ \\
WhatsApp & $85 \%$ \\
LinkedIn & $1 \%$ \\
Google Plus & $27 \%$ \\
Instagram & $1.5 \%$ \\
Others & $0 \%$ \\
\hline
\end{tabular}

When asked about the most prominent social sites that they are using for their teaching purposes, most of the teachers say that they prefer WhatsApp. The most important reason for their choice of WhatsApp is that it's very handy and it can be used for one to one correspondence as well as correspondences with groups. WhatsApp is considered the user-friendliest application of all the available apps. Table 5 gives us the details of the responses of teachers to questions 14 and 15 that are specifically meant for the qualitative analysis purpose.

\section{Conclusion}

The analysis of the data shows that majority of EFL teachers are looking at the social networking sites for the easiness that the sites offer in finding and distributing authentic and instructional teaching materials. They also think that the sites are the most common communication tools for the people in all occupations. So, the question related to the distribution of materials has got greater percent of agreement with the statement. The role of social net-working sites is considered to be prominent and the integration of social networking sites in teaching is in practice with a complete knowledge of the teachers about the sites that they are using. However, the teachers feel that continuous in-service trainings can support them with the ever-upgrading technological advancements. Teachers always need to keep upgrading themselves in terms of their teaching styles, methods and modes of their teaching and need to get their teaching activities sync with the ever-developing technological innovations. When teaching methods and modes are technologically on par with the learners' knowledge of technology and their styles of learning, teaching becomes more meaningful and productive. In this regard, the outcomes of the study turn out to enlighten teachers about the use of social networking as a means of productive teaching, which in turn helps in upgrading themselves into tech-savvy professionals.

\section{References}

Andrei, E. (2017). Technology in teaching English language learners: The case of three middle school teachers. TESOL Journal, 8(2), 409-431. https://doi.org/10.1002/tesj.280

Bernheim, B., \& Exley, C. (2015). Understanding conformity: an experimental investigation. Working Paper, Harvard Business School. https://doi.org/10.2139/ssrn.2703932

Blattner, G., \& Fiori, M. (2009). Facebook in the language classroom: Promises and possibilities. International Journal of Instructional Technology and Distance Learning, 6(1), 17-28. Retrieved from http://www.itdl.org/Journal/Jan_09/Jan_09.pdf\#page=21

Boas, I. V. (2011). Process Writing and the Internet: Blogs and Ning Networks in the Classroom. In English Teaching Forum (Vol. 49, No. 2, pp. 26-33). US Department of State. Bureau of Educational and Cultural Affairs, Office of English Language Programs, SA-5, 2200 C Street NW 4th Floor, Washington, DC 20037. Retrieved from https://files.eric.ed.gov/fulltext/EJ962381.pdf

Bosch, T. E. (2009). Using online social networking for teaching and learning: Facebook use at the University of Cape Town. Communication: South African Journal for Communication Theory and Research, 35(2), 185 200. https://doi.org/10.1080/02500160903250648 
Carter, H. L., Foulger, T. S., \& Ewbank, A. D. (2008). Have you googled your teacher lately? Teachers' use of social networking sites. Phi Delta Kappan, 89(9), 681-685. https://doi.org/10.1177/003172170808900916

Chartrand, R. (2012). Social networking for language learners: Creating meaningful output with Web 2.0 tools. Knowledge Management \& E-Learning: An International Journal, 4(1), 97-101. Retrieved from http://kmel-journal.org/ojs/index.php/online-publication/article/viewFile/170/124

Dooly, M., \& Masats, D. (2010). Closing the loop between theory and praxis: new models in EFL teaching. ELT Journal, 65(1), 42-51. https://doi.org/10.1093/elt/ccq017

Galien, P., \& Bowcher, W. L. (2010). Using blogs in ESL/EFL teaching and teacher-training. Asian EFL Journal, 42, 4-23. Retrieved from https://docs.google.com/viewerng/viewer?url=http://asian-efl-journal.com/pta-February-2010.pdf\&hl=en_U $\mathrm{S}$

George, D., \& Mallery, P. (2003). SPSS for Windows step by step: A simple guide and reference. 11.0 update (4th ed.). Boston: Allyn \& Bacon. Retrieved from https://wps.ablongman.com/wps/media/objects/385/394732/george4answers.pdf

Jenness, A. (1932). The Role of Discussion in Changing Opinions Regarding a Matter of Fact. Journal of Abnormal Social Psychology, 27, 279-296. https://doi.org/10.1037/h0074620

Lawrence, E. E., \& Latha, R. (2015, March). Analysis of six degrees of separation in Facebook using Ant colony optimization (pp. 1-5). In Circuit, Power and Computing Technologies (ICCPCT), 2015 International Conference on IEEE. https://doi.org/10.1109/ICCPCT.2015.7159171

Miyazoe, T., \& Anderson, T. (2010). Learning outcomes and students' perceptions of online writing: Simultaneous implementation of a forum, blog, and wiki in an EFL blended learning setting. System, 38(2), 185-199. https://doi.org/10.1016/j.system.2010.03.006

Prensky, M. (2001). Digital natives, digital immigrants part 1. On the horizon, 9(5), 1-6. https://doi.org/10.1108/10748120110424816

Roblyer, M. D., McDaniel, M., Webb, M., Herman, J., \& Witty, J. V. (2010). Findings on Facebook in higher education: A comparison of college faculty and student uses and perceptions of social networking sites. The Internet and Higher Education, 13(3), 134-140. https://doi.org/10.1016/j.iheduc.2010.03.002

Rouse, M (n.d). Social Networking, TechTarget. Retrieved from https://whatis.techtarget.com/definition/social-networking

Santos, J. R. A. (1999). Cronbach's alpha: A tool for assessing the reliability of scales. Journal of Extension, 37(2), 1-5. Retrieved from https://www.joe.org/joe/1999april/tt3.php/journal-current-issue.php

Tess, P. A. (2013). The role of social media in higher education classes (real and virtual) -A literature review. Computers in Human Behavior, 29(5), A60-A68. https://doi.org/10.1016/j.chb.2012.12.032

Wu, W. C. V., Yen, L. L., \& Marek, M. (2011). Using online EFL interaction to increase confidence, motivation, and ability. Journal of Educational Technology \& Society, 14(3). Retrieved from http://www.ifets.info/journals/14_3/10.pdf

Yang, S. H. (2009). Using blogs to enhance critical reflection and community of practice. Journal of Educational Technology \& Society, 12(2). Retrieved from http://www.ifets.info/journals/12_2/2.pdf

\section{Appendix A}

1) Social networking sites like Facebook, messenger, Twitter, Instagram and WhatsApp are the most powerful media of communication.

2) I use social networking sites for most of my communication purposes with the people I regularly interact.

3) Limitations in the Internet access at my place makes me constrained to use it occasionally and only for important activities.

4) I am aware that the social networking sites are great communication tools for pedagogical purposes.

5) Using social networking sites is a part of my teaching method.

6) I consider using social networking sites in teaching as a productive instructional method for the current generation. 
7) I think that all the teachers of English language have got used to integrating social networking sites in their language instructional process.

8) Distributing work sheets and copies of the instructional materials is much easier by using the social networking Apps in mobile phones and electronic notebooks.

9) Social Networking is a great platform for the Maintenance of group communications in English language, and the communication process improves the language and communication skills of the users.

10) I can control and confine my communication with the groups of my students on social networking sites to the topics relevant to my teaching, so that I can maintain my teacher authority and my teacher status.

11) Using social networking sites supports in improving the scores of students in both the formative as well as summative tests.

12) The social networking sites are playing a major role in changing the student classroom behaviors with regard to their status of being the followers of prescribed classroom norms to the status of being self-styled reflective thinkers and autonomous learners.

13) Integration of social networking sites can minimize the role of teachers much more as supervisors leading the learners to become more autonomous and interactive.

14) I use the following online social networking sites for my regular social interaction with my family, friends and acquaintances (Please tick all the applications that you use).
a) Facebook
b) WhatsApp
c) Twitter
d) Instagram
e) other f) none

15) I use the following online social networking sites in classrooms as part of my teaching methodology (Please tick all the applications that you use).
a) Facebook
b) WhatsApp
c) Twitter
d) Instagram
e) other
f) none

\section{Copyrights}

Copyright for this article is retained by the author, with first publication rights granted to the journal.

This is an open-access article distributed under the terms and conditions of the Creative Commons Attribution license (http://creativecommons.org/licenses/by/4.0/). 